\title{
Kecemasan mahasiswa teknik komputer dan jaringan dalam menghadapi ujian praktik kejuruan
}

\author{
Lisa Putriani ${ }^{1}$, Tyesa Sri Handayuni ${ }^{2}$, Yola Eka Putri ${ }^{3}$, Ifdil Ifdi1 ${ }^{4^{*}}$ \\ ${ }^{1234}$ Universitas Negeri Padang, Indonesia
}

\begin{tabular}{l}
\hline Article Info \\
\hline Article history: \\
Received Jun 11th, 2020 \\
Revised Jul 03rd, 2020 \\
Accepted Aug 10th, 2020
\end{tabular}

\section{Keyword:}

Anxiety

\begin{abstract}
The high level of student anxiety when facing exams causes negative effects that come from internal and external factors. Anxiety is an emotional state that is not soothing, such as feeling depressed in the face of adversity or before it occurs, which is characterized by feelings of worry, tension, and fear in certain situations. This study aims to describe the anxiety of vocational high school students in terms of cognitive, affective, and behavioral aspects. This research is quantitative research with descriptive methods. With a sample of 115 students using a proportional random sampling technique. The data were obtained by providing anxiety instruments in the face of vocational practice exams. Data were analyzed descriptively by determining the mean, standard deviation, and percentage. The results of the study reveal that the first, the level of anxiety of students majoring in Computer and Network Engineering in facing vocational practice exams is generally in the low category. Second, the level of anxiety of students majoring in Computer and Network Engineering in facing vocational practice exams seen from the cognitive aspect is generally in the medium category. Third, the level of anxiety of students majoring in Computer and Network Engineering in facing vocational practice exams seen from the affective aspect is generally in the medium category. Fourth, the level of anxiety of students majoring in Computer and Network Engineering in facing vocational practice exams seen from the aspect of behavior is generally in the medium category.
\end{abstract}

(C) 2020 The Authors. Published by the Indonesian Institute for Counseling Education, and Therapy (IICET). This is an open-access article under the CC BY license (https://creativecommons.org/licenses/by/4.0/)

\section{Corresponding Author:}

Ifdil Ifdil

Universitas Negeri Padang

Email: ifdil@konselor.org

\section{Pendahuluan}

Perkembangan merupakan pola individu yang berawal pada konsep dan terus berlanjut sepanjang hayat serta bersifat involusi (Marina, 2017). Aspek-aspek yang menunjukkan bahwa individu dalam perkembangan meliputi aspek fisik, intelektual, emosi dan perasaan, bahasa dan perilaku kognitif, kepribadian, perkembangan moral, perkembangan sosial, minat, motivasi, sikap, bakat, serta kreativitas (Pavlova, 2020). Perkembangan manusia dibagi menjadi beberapa tahapan yang dimulai dari dalam kandungan (masa prenatal), masa bayi, masa anak-anak, masa remaja, masa dewasa, dan lanjut usia (Jahja, 2011).

Masa remaja adalah usia di mana individu berintegrasi dengan masyarakat dewasa, usia di mana anak tidak lagi merasa di bawah tingkat orang-orang yang lebih tua melainkan berada dalam tingkatan yang sama (S. Y. Sari, 2017). Remaja yang berusia 13-19 tahun mengalami banyak perubahan secara kognitif, emosional, fisiologis, psikologis dan sosial (Richards, 2010) 
Peraturan Menteri Pendidikan dan Kebudayaan Republik Indonesia Nomor 17 Tahun 2017 tentang Penerimaan Peserta Didik Baru pada Taman Kanak-Kanak (TK), Sekolah Dasar (SD), Sekolah Menengah Pertama (SMP), Sekolah Menengah Atas (SMA), Sekolah Menengah Kejuruan (SMK), atau bentuk lain yang sederajat menetapkan salah satu persyaratan calon peserta didik baru kelas 10 (sepuluh) SMA, SMK, atau bentuk lain yang sederajat ialah berusia paling tinggi 21 tahun.

Sekolah Menengah Kejuruan (SMK) merupakan suatu lembaga pendidikan menengah yang menyelenggarakan program pendidikan tiga tahun setelah Sekolah menengah Pertama (SMP), dengan hasil yang diharapkan siswanya siap terjun di dunia kerja setelah lulus dari bangku sekolah. Pada pendidikan SMK, pengetahuan tidak hanya satu-satunya bekal bagi siswa, melainkan keterampilan atau kompetensi sesuai bidang juga merupakan hal penting yang harus dikuasai siswa sebagai bekal untuk terjun ke dunia kerja, karena materi teori dan praktik yang dilakukan sudah diberikan sejak siswa pertama masuk SMK (Adam \& Wahyu Cahyaka, 2019; Fadli, Alizamar, \& Afdal, 2017) (Jatmoko, 2013). Menurut Nugroho Wibowo dalam (Prasetyo, 2017) Pengembangan diri secara profesional juga sangat diperlukan oleh siswa, agar siswa tetap mampu berkompetisi pada saat ini maupun masa yang akan datang dengan menyesuaikan perkembangan dan tuntutan jaman.

Tantangan yang harus dihadapi dan trauma yang terus-menerus, kemudian tidak tertangani akan menyebabkan munculnya kecemasan dalam diri siswa (Ramaiah, 2003). Kecemasan itulah yang secara otomatis menyebabkan penghindaran terhadap sumber kecemasan (Anita, 2014). Jika ini dibiarkan, maka akan mempengaruhi kondisi psikologis dan emosi siswa, baik saat belajar maupun saat berinteraksi dengan mata pelajaran yang menjadi sumber kecemasan.

Kecemasan adalah suatu keadaan yang membuat seseorang tidak merasa nyaman terhadap situasi-situasi yang menakutkan atau mengancam dan terbagi dalam beberapa tingkatan (Nurlaila, 2011; Siregar, 2019). Ancaman itu dapat menimbulkan perasaan yang tidak menyenangkan yang ditandai dengan ketegangan yang diiringi perasaan takut khawatir dan gelisah, sehingga tidak mampu merespon bahaya tersebut dengan wajar (Pranoto, 2017). Menurut Frank (Puspitasari \& Aristawati, 2020) kecemasan dapat dirasakan bila seseorang menghadapi objek atau situasi yang dikhawatirkan dalam gangguan komplusif.

Siswa yang cemas ketika akan menghadapi ujian merupakan hal yang wajar selama kecemasannya masih dalam kategori rendah, namun kecemasan yang berlebihan ketika akan menghadapi ujian tentunya akan berdampak pada terganggunya proses belajar siswa, dan dapat menghambat pelaksanaan ujian (Apriliana, 2018; Permatasari, Rahajeng, Fitriani, \& Kurniawati, 2018).

Berdasarkan hasil penelitian Qausarina (2016) tentang pengaruh kecemasan matematika (Math anxiety) terhadap hasil belajar matematika siswa kelas X SMA N 11 Banda Aceh, terdapat hubungan positif yang signifikan antara kecemasan matematika (math anxiety) terhadap hasil belajar matematika siswa kelas X IPA SMA N 11 Banda Aceh. Hasil penelitian NI Komang (2012) tentang Hubungan tingkat kecemasan terhadap koping siswa SMU N 16 dalam menghadapi ujian nasional, menyatakan terdapat hubungan antara tingkat kecemasan terhadap koping siswa dalam menghadapi ujian nasional.

Berdasarkan penjelasan yang telah dipaparkan dan hasil penelitian terdahulu, maka penelitian ini dilakukan untuk melihat bagaimana tingkat kecemasan dalam menghadapi ujian praktik kejuruan oleh siswa jurusan Teknik Komputer dan Jaringan. Kemudian hasil penelitian yang diperoleh akan menjadi pertimbangan bagi guru bimbingan dan konseling atau konselor untuk menentukan layanan yang akan diberikan kepada siswa yang mengalami kecemasan saat menghadapi ujian praktik kejuruan.

\section{Metode}

Penelitian ini menggunakan jenis penelitian kuantitatif dengan pendekatan deskriptif yang bertujuan untuk menggambarkan tingkat kecemasan yang dirasakan siswa Teknik Komputer dan Jaringan saat menghadapi ujian praktik kejuruan. Sampel penelitian berjumlah 115 siswa, siswa laki-laki berjumlah 52 orang dan siswa perempuan berjumlah 63 orang. Penelitian ini dilakukan di SMK N 5 Solok Selatan. Proses pengumpulan data dilakukan menggunakan instrumen kecemasan siswa dalam menghadapi ujian praktik kejuruan, dengan model skala Likert. Data hasil penelitian di analisis menggunakan teknik analisis deskriptif. 


\section{Hasil dan Pembahasan}

Berdasarkan hasil pengolahan data, maka hasil penelitian yang dilakukan di SMK N 5 Solok Selatan dapat dijelaskan sebagai berikut.

Kecemasan siswa dalam menghadapi ujian praktik kejuruan

Berdasarkan hasil pengolahan data, dapat digambarkan kecemasan dalam menghadapi ujian praktik kejuruan pada siswa jurusan Teknik Komputer dan Jaringan (TKJ) SMK N 5 Solok Selatan seperti berikut ini:

Tabel 1. Kecemasan Siswa dalam Menghadapi Ujian Praktik Kejuruan

\begin{tabular}{lccc}
\hline Kategori & Interval Skor & F & \% \\
\hline Sangat Tinggi & $\geq 108$ & 8 & 6,96 \\
Tinggi & $\geq 95 \mathrm{~s} / \mathrm{d}<108$ & 32 & 27,83 \\
Sedang & $\geq 82 \mathrm{~s} / \mathrm{d}<95$ & 33 & 28,7 \\
Rendah & $\geq 69 \mathrm{~s} / \mathrm{d}<82$ & 35 & 30,43 \\
Sangat Rendah & $<69$ & 7 & 6,09 \\
& & 115 & 100 \\
\hline
\end{tabular}

Berdasarkan tabel 1, dapat diketahui tingkat kecemasan dalam menghadapi ujian praktik kejuruan pada siswa jurusan Teknik Komputer dan Jaringan SMK N 5 Solok Selatan pada umumnya berada pada kategori rendah dengan persentase 30,43\% (35 orang), selanjutnya siswa yang mengalami kecemasan saat menghadapi ujian praktik kejuruan berada pada kategori sangat tinggi dengan persentase $6,96 \%$ ( 8 orang), berada pada kategori tinggi dengan persentase 27,83\% (32 orang), kemudian tingkat kecemasan siswa saat menghadapi ujian praktik kejuruan berada pada kategori sedang dengan persentase $28,7 \%$ (33 orang), dan pada kategori sangat rendah dengan persentase $6,09 \%$ (7 orang). Temuan ini mengungkapkan kondisi kecemasan siswa jurusan Teknik Komputer dan Jaringan SMK N 5 Solok Selatan dalam menghadapi ujian praktik kejuruan pada umumnya berada pada kategori rendah, dalam hal ini berarti siswa jurusan Teknik Komputer dan jaringan (TKJ) di SMK N 5 Solok Selatan sudah cukup siap dalam menghadapi ujian praktik kejuruan.

Kecemasan didefinisikan sebagai perasaan yang terkadang mendorong individu untuk melakukan hal-hal perilaku yang positif dan kreatif dengan memotivasi kehidupannya dalam seahari-hari, namun juga dapat menghambat perilaku positifnya sehingga menimbulkan kegelisahan pada dirinya. Kecemasan saat ujian menimbulkan reaksi berupa ketidakseimbangan yang dirasakan antara tuntutan yang berbeda, tuntutan ini menyangkut dengan intelektual siswa, kemampuan dan motivasi, serta sosial yang dapat berasal dari diri individu, dari orang lain yang signifikan, atau dari sekolah (Schwarzer, 1982). Kecemasan saat ujian berdampak negatif bagi siswa jika kecemasan tersebut ditangani dengan cara yang tidak sehat dan berlangsung lama. Tingkat kecemasan siswa saat ujian dapat menyebabkan berbagai hasil negatif terutama pada nilai akademik yang rendah. Namun, pengelolaan diri yang baik dapat memberikan efek yang positif (Barrows, Dunn, \& Lloyd, 2013).

\section{Aspek kognitif}

Berdasarkan hasil pengolahan data, dapat digambarkan kecemasan dalam menghadapi ujian praktik kejuruan pada siswa jurusan Teknik Komputer dan Jaringan (TKJ) SMK N 5 Solok Selatan dilihat dari aspek kognitif seperti berikut ini:

Tabel 2. Kecemasan Siswa dalam Menghadapi Ujian Praktik Kejuruan Dilihat dari Aspek Kognitif

\begin{tabular}{lccc}
\hline Kategori & Interval Skor & F & \% \\
\hline Sangat Tinggi & $\geq 49$ & 8 & 6,96 \\
Tinggi & $\geq 43 \mathrm{~s} / \mathrm{d}<49$ & 34 & 29,57 \\
Sedang & $\geq 37 \mathrm{~s} / \mathrm{d}<43$ & 44 & 38,26 \\
Rendah & $\geq 31 \mathrm{~s} / \mathrm{d}<37$ & 26 & 22,61 \\
Sangat Rendah & $<31$ & 3 & 2,61 \\
$\quad$ Jumlah & & 115 & 100 \\
\hline
\end{tabular}

Berdasarkan tabel 2, dapat diketahui tingkat kecemasan dalam menghadapi ujian praktik kejuruan dilihat dari aspek kognitif pada siswa jurusan Teknik Komputer dan Jaringan SMK N 5 Solok Selatan pada umumnya berada pada kategori sedang dengan persentase 38,26\% (44 orang), siswa yang mengalami tingkat 
kecemasan saat menghadapi ujian praktik kejuruan berada pada kategori sangat tinggi dengan persentase $6,96 \%$ (8 orang), kemudian berada pada kategori tinggi dengan persentase $29,57 \%$ (34 orang), selanjutnya siswa yang mengalami kecemasan saat menghadapi ujian praktik kejuruan berada pada kategori rendah dengan persentase $22,61 \%$ (26 orang), dan pada kategori sangat rendah dengan persentase $2,61 \%$ ( 3 orang). Temuan ini mengungkapkan kondisi kecemasan siswa jurusan TKJ dalam menghadapi ujian praktik kejuruan dilihat dari aspek kognitif pada umumnya berada pada kategori sedang.

Kecemasan yang dialami meliputi kemampuan memecahkan masalah dalam menghadapi ujian praktik kejuruan, motivasi untuk mengikuti ujian praktik kejuruan yang akan mempengaruhi kognitif diri siswa, serta pengontrolan diri saat menghadapi ujian praktik kejuruan baik dari dalam diri siswa maupun dari orang-orang di lingkungan sekitar (Zeidner, 1998). Terlalu cemas menjelang ujian akan mengganggu kejernihan pikiran, keinginan untuk belajar, ketangguhan diri dan daya ingat untuk belajar dengan efektif (A. W. Sari, Mudjiran, \& Alizamar, 2017).

\section{Aspek afektif}

Berdasarkan hasil pengolahan data, digambarkan kecemasan dalam menghadapi ujian praktik kejuruan pada siswa jurusan Teknik Komputer dan Jaringan (TKJ) SMK N 5 Solok Selatan dilihat dari aspek kognitif seperti berikut ini:

Tabel 3. Kecemasan Siswa dalam Menghadapi Ujian Praktik Kejuruan Dilihat dari Aspek Afektif

\begin{tabular}{lccc}
\hline Kategori & Interval Skor & F & \% \\
\hline Sangat Tinggi & $\geq 36$ & 8 & 6,96 \\
Tinggi & $\geq 30 \mathrm{~s} / \mathrm{d}<36$ & 31 & 26,96 \\
Sedang & $\geq 24 \mathrm{~s} / \mathrm{d}<30$ & 45 & 39,13 \\
Rendah & $\geq 18 \mathrm{~s} / \mathrm{d}<24$ & 23 & 20 \\
Sangat Rendah $\quad$ Jumlah & $<18$ & 8 & 6,96 \\
$\quad$ & 115 & 100 \\
\hline
\end{tabular}

Berdasarkan tabel 3, dapat diketahui tingkat kecemasan dalam menghadapi ujian praktik kejuruan dilihat dari aspek afektif pada siswa jurusan Teknik Komputer dan Jaringan SMK N 5 Solok Selatan pada umumnya berada pada kategori sedang dengan persentase 39,13\% (45 orang), siswa yang mengalami tingkat kecemasan saat menghadapi ujian praktik kejuruan berada pada kategori sangat tinggi dengan persentase $6,96 \%$ ( 8 orang), kemudian berada pada kategori tinggi dengan persentase 26,96\% (31 orang), selanjutnya siswa yang mengalami kecemasan saat menghadapi ujian praktik kejuruan berada pada kategori rendah dengan persentase $20 \%$ (23 orang), dan pada kategori sangat rendah dengan persentase $6,96 \%$ (8 orang). Temuan ini mengungkapkan kondisi kecemasan siswa jurusan Teknik Komputer dan Jaringan (TKJ) SMK N 5 Solok Selatan dalam menghadapi ujian praktik kejuruan dilihat dari aspek afektif pada umumnya berada pada kategori sedang.

Kecemasan adalah emosi yang tidak menyenangkan yang ditandai dengan kekhawatiran, keprihatinan, dan rasa takut (A. W. Sari, et al., 2017) kecemasan adalah suatu keadaan khawatir yang mengeluhkan bahwa sesuatu yang buruk akan terjadi. Kecemasan yang siswa alami meliputi reaksi fisiologis seperti gangguan pada lambung, berkeringat, tangan dingin, buang air kecil, mulut kering, tangan gemetar dan jantung berdetak kencang, serta reaksi emosional seperti khawatir, takut, cemas, dan tegang (Concannon, Esmail, \& Roberts, 2020; Zeidner, 1998). Sejalan dengan Istiqomah \& Habsy (2019) siswa yang mengalami kecemasan mengalami ujung-ujung jari terasa dingin, pencernaan kurang teratur, keringat bercucuran, jantung berdetak cepat, dan sangat takut. Kecemasan siswa dicirikan dengan kegelisahan, kekhawatiran, ketakutan yang akan terjadi pada hal-hal yang tidak diinginkan termasuk prestasi akademik (Handayani, 2019; Mousa, et al.).

\section{Aspek perilaku}

Berdasarkan hasil pengolahan data, digambarkan kecemasan dalam menghadapi ujian praktik kejuruan pada siswa jurusan Teknik Komputer dan Jaringan (TKJ) SMK N 5 Solok Selatan dilihat dari aspek perilaku seperti berikut ini:

Berdasarkan tabel 4, dapat diketahui tingkat kecemasan dalam menghadapi ujian praktik kejuruan dilihat dari aspek perilaku pada siswa jurusan Teknik Komputer dan Jaringan SMK N 5 Solok Selatan pada umumnya berada pada kategori sedang dengan persentase 35,65\% (41 orang), berada pada kategori sangat tinggi dengan persentase $6,09 \%$ ( 7 orang), kemudian berada pada kategori tinggi dengan persentase $22,61 \%$ (26 orang), berada pada kategori rendah dengan persentase 31,3\% (36 orang), dan pada kategori sangat rendah 
dengan persentase 4,35\% (5 orang). Temuan ini mengungkapkan kondisi kecemasan siswa jurusan TKJ SMK N 5 Solok selatan dalam menghadapi ujian praktik kejuruan dilihat dari aspek perilaku pada umumnya berada pada kategori sedang.

Tabel 4. Kecemasan Siswa dalam Menghadapi Ujian Praktik Kejuruan Dilihat dari Aspek Perilaku

\begin{tabular}{lccc}
\hline Kategori & Interval Skor & F & \% \\
\hline Sangat Tinggi & $\geq 29$ & 7 & 6,09 \\
Tinggi & $\geq 24 \mathrm{~s} / \mathrm{d}<29$ & 26 & 22,61 \\
Sedang & $\geq 19 \mathrm{~s} / \mathrm{d}<24$ & 41 & 35,65 \\
Rendah & $\geq 14 \mathrm{~s} / \mathrm{d}<19$ & 36 & 31,3 \\
Sangat Rendah & $<14$ & 5 & 4,35 \\
$\quad$ Jumlah & & 115 & 100 \\
\hline
\end{tabular}

Kecemasan yang dialami meliputi menunda-nunda, menghindar, dan melarikan diri (Zeidner, 1998). Perilaku terbentuk dari pengalaman akan kecemasan yang menekankan pada proses yang dialami sebelumnya yang kemudian dimunculkan sebagai bentuk proses dari respon cemas (Nurlaila, 2011).

\section{Simpulan}

Hasil penelitian mengungkapkan, (1) tingkat kecemasan siswa jurusan Teknik Komputer dan Jaringan dalam menghadapi ujian praktik kejuruan pada umumnya berada pada kategori rendah. (2) tingkat kecemasan siswa jurusan Teknik Komputer dan Jaringan dalam menghadapi ujian praktik kejuruan dilihat dari aspek kognitif pada umumnya berada pada kategori sedang. (3) tingkat kecemasan siswa jurusan Teknik Komputer dan Jaringan dalam menghadapi ujian praktik kejuruan dilihat dari aspek afektif pada umumnya berada pada kategori sedang. (4) tingkat kecemasan siswa jurusan Teknik Komputer dan Jaringan dalam menghadapi ujian praktik kejuruan dilihat dari aspek perilaku pada umumnya berada pada kategori sedang.

\section{Referensi}

Adam, B., \& Wahyu Cahyaka, H. (2019). Penerapan Model Pembelajaran Project Based Learning dengan Menggunakan Media Sketchup pada Mata Pelajaran Konstruksi dan Utilitas Gedung Kelas XI Di SMK Negeri 2 Bojonegoro. Jurnal Kajian Pendidikan Teknik Bangunan, 5(2).

Anita, I. W. (2014). Pengaruh kecemasan matematika (mathematics anxiety) terhadap kemampuan koneksi matematis siswa SMP. Infinity Journal, 3(1), 125-132.

Apriliana, I. P. A. (2018). Tingkat kecemasan siswa SMK menghadapi ujian nasional berbasis komputer tahun 2018. Counsellia: Jurnal Bimbingan dan Konseling, 8(1), 37-44.

Barrows, J., Dunn, S., \& Lloyd, C. A. (2013). Anxiety, Self-Efficacy, and College Exam Grades. Universal Journal of Educational Research, 1(3), 204-208.

Concannon, B. J., Esmail, S., \& Roberts, M. R. (2020). Immersive Virtual Reality for the Reduction of State Anxiety in Clinical Interview Exams: Prospective Cohort Study. JMIR Serious Games, 8(3), e18313.

Fadli, R. P., Alizamar, A., \& Afdal, A. (2017). Persepsi siswa tentang kesesuaian perencanaan arah karir berdasarkan pilihan keahlian siswa sekolah menengah kejuruan. Konselor, 6(2), 74-82.

Handayani, S. D. (2019). Pengaruh Kecemasan Matematika terhadap Pemahaman Konsep Matematika. SAP (Susunan Artikel Pendidikan), 4(1).

Istiqomah, D., \& Habsy, B. A. (2019). Keefektifan konseling realita untuk mengatasi kecemasan mengemukakan pendapat pada siswa SMP. Indonesian Journal of Educational Counseling, 3(1), 61-70.

Jahja, Y. (2011). Psikologi perkembangan, jakarta. Kencana Media Group.

Jatmoko, D. (2013). Relevansi kurikulum SMK kompetensi keahlian teknik kendaraan ringan terhadap kebutuhan dunia industri di Kabupaten Sleman. Jurnal Pendidikan Vokasi, 3(1).

Marina, Y. (2017). Bimbingan Kelompok dalam Mengembangkan Konsep Diri Remaja Panti Asuhan Abdul Malik Muhammad Aliyun Way Kandis Tanjung Senang Bandar Lampung. UIN Raden Intan Lampung.

Mousa, O., Alnasser, H. S., Alnwiaser, M. M., Alsaleh, H. N., Alhamadah, Z. T., \& Almubarak, M. H. Level of Test Anxiety for Final Exam among King Faisal University Students. 
Nurlaila, S. (2011). Pelatihan efikasi diri untuk menurunkan kecemasan pada siswa-siswi yang akan menghadapi ujian akhir nasional. GUIDENA: Jurnal Ilmu Pendidikan, Psikologi, Bimbingan dan Konseling, $1(1), 1-22$.

Pavlova, O. (2020). Relations between organizational culture and human resources management in a modern organization. [Article]. Informacijos Mokslai, 88, 105-119.

Permatasari, D. P., Rahajeng, U. W., Fitriani, A., \& Kurniawati, Y. (2018). Parent's academic expectation dan Konsep Diri Akademik Terhadap Kecemasan Menghadapi Ujian Nasional siswa SMA. Jurnal Ilmiah Psikologi Terapan, 6(1), 63-73.

Pranoto, H. (2017). Layanan bimbingan kelompok dalam mengurangi kecemasan peserta didik menghadapi ujian atau tes. Paper presented at the Prosiding Seminar Nasional Pendidikan.

Prasetyo, A. B. (2017). Kelayakan Sarana Prasarana Pembelajaran pada Kompetensi Keahlian Teknik Pengelasan Di SMK Negeri 2 Pengasih. Jurnal Pendidikan Vokasional Teknik Mesin, 5(5), 333-338.

Puspitasari, R. H., \& Aristawati, E. (2020). Hubungan Tingkat Kecemasan Wanita Pra Menopause Dengan Masa Pra Menopause Di MI Miftakhul Ulum Kabupaten Pasuruan. Jurnal Ilmiah Keperawatan, 15(1), 100-106.

Qausarina, H. (2016). Pengaruh Kecemasan Matematika (Math Anxiety) Terhadap Hasil Belajar Matematika Siswa Kelas X SMA Negeri 11 Banda Aceh. UIN Ar-Raniry Banda Aceh.

Ramaiah, S. (2003). Kecemasan, bagaimana mengatasi penyebabnya: Yayasan Obor Indonesia.

Ratih, N. K., Fitriyani, P., \& Nurviyandari, D. (2012). Hubungan tingkat kecemasan terhadap koping siswa SMUN 16 dalam menghadapi ujian nasional. Skripsi tidak dipublikasi). FIK-Universitas Indonesia, Depok, Jawa Barat.

Richards, G. (2010). Serial konsep-konsep kunci psikologi. Yogyakarta: Pustaka Baca.

Sari, A. W., Mudjiran, M., \& Alizamar, A. (2017). Tingkat Kecemasan Siswa dalam Menghadapi Ujian Sekolah Ditinjau dari Jenis Kelamin, Jurusan dan Daerah Asal Serta Implikasi. Bikotetik (Bimbingan dan Konseling: Teori dan Praktik), 1(2), 37-42.

Sari, S. Y. (2017). Tinjauan Perkembangan Psikologi Manusia pada Usia Kanak-Kanak dan Remaja. Primary Education Journal (PEJ), 1(1), 46-50.

Schwarzer, R. (1982). Advances in test anxiety research (Vol. 1): Lawrence Erlbaum Assoc Incorporated.

Siregar, A. H. (2019). Teknologi Informasi dan Pengaruhnya Terhadap Tingkat Kecemasan Bekerja Karyawan di Bank. Jurnal Ilmiah SMART, 3(2), 47-59.

Zeidner, M. (1998). Anxiety (the state of the art). New York: Kluwer Academic Publishers. 